\title{
Real-time Aspect on the Application Implementation of Chronic Disease Management Program Patients in supporting Clinical Documentation Improvement (CDI)
}

\author{
Rinda Nurul Karimah \\ Program Studi Rekam Medik \\ Jurusan Kesehatan \\ Politeknik Negeri Jember \\ Jember, Indonesia \\ rindank6@gmail.com \\ Izatul Milla \\ Program Studi Rekam Medik \\ Jurusan Kesehatan \\ Politeknik Negeri Jember \\ Jember, Indonesia \\ Izatulmilla@gmail.com
}

\author{
Sustin Farlinda \\ Program Studi Rekam Medik \\ Jurusan Kesehatan \\ Politeknik Negeri Jember \\ Jember, Indonesia \\ sustin@polije.ac.id
}

\author{
Lailatu Taufiqoh \\ RSIA Citra Keluarga \\ Kediri, Indonesia \\ Lailatutaufiqoh29@gmail.com
}

\begin{abstract}
Abstrak- Chronic Disease Management Program (PROLANIS) is one of programs conducted by Indonesian Healthcare Social Insurance Organization. Prolanis program's target is making chronic disease patient achieve the optimal quality of life through the effective and efficient health service costs and prevent any disease complications [3]. Prolanis activities consist of medical or educational consultation, reminder, club activities and health-status monitoring which is done periodically. Clinical Documentation Improvement (CDI) is a program facilitating the realization of patients' accurate clinical-status. Prolanis application was made to monitor the health status patients periodically but the achievements never are not yet known regarding CDI. An evaluation must be done especially on real-time aspect to make prolanis application perfect. This research was descriptive and quantitative analytic research with cross sectional approach by using scoring method. The research results revealed that the value of information quality on real-time aspect regarding the implementation of prolanis application on overall score interpretation was in good category $(\mathbf{7 9 , 3 \%} \%)$. The highest real-time aspect was found in the patients' identity items written on BPJS cards and the health chart was $83,3 \%$, while the lowest item of personnel data and DM report was $73,3 \%$. These analysis results can be used to make prolanis application more perfect so that it will fulfill the needs of CDI.
\end{abstract}

Keywords - clinical documentation improvement (CDI); prolanis; realtime

Abstrak - Program Pengelolaan Penyakit Kronis (PROLANIS) merupakan salah satu program dari Badan Pelaksana Jaminan Sosial (BPJS) Kesehatan untuk pemeliharaan kesehatan peserta BPJS Kesehatan yang menderita penyakit kronis. Target capaian program prolanis adalah agar pasien penyakit kronis dapat mencapai kualitas hidup yang optimal dengan biaya pelayanan kesehatan yang efektif dan efisien serta dapat mencegah timbulnya komplikasi penyakit[3]. Kegiatan Prolanis meliputi aktifitas konsultasi medis atau edukasi, kunjungan rumah (home visit), reminder, aktifitas klub dan pemantauan status kesehatan secara berkala dan termonitor. Clinical Documentation Improvement (CDI) merupakan program yang memfasilitasi terwujudnya akurasi dari status klinis pasien yang akan menjadi data kode. Aplikasi prolanis dibangun untuk pemantauan pasien prolanis berbasis web sebagai solusi pemantauan status kesehatan pasien prolanis secara periodik tetapi belum pernah diketahui apakah aplikasi telah memenuhi CDI. Evaluasi harus dilakukan terutama pada aspek tepat waktu untuk menyempurnakan aplikasi. Jenis penelitian dalam penelitian ini adalah penelitian deskriptif dan analitik kuantitatif dengan pendekatan cross sectional menggunakan metode skoring. Hasil penelitian diperoleh nilai kualitas informasi khususnya aspek tepat waktu terkait penerapan aplikasi prolanis dengan interpretasi skor secara keseluruhan pada item berada pada kategori baik $(79,3 \%)$. Item aspek tepat waktu tertinggi terdapat pada item identitas pasien sesuai kartu BPJS dan grafik kesehatan sebesar 83,3\% dan item terendah pada item data petugas dan laporan DM sebesar 73,3\%. Hasil analisis tersebut ditujukan untuk menyempurnakan aplikasi prolanis agar tepat sasaran sesuai kebutuhan khususnya keperluan CDI.

Keywords - prolanis; , clinical documentation improvement (CDI); tepat waktu 


\section{PENDAHULUAN}

Program Pengelolaan Penyakit Kronis (PROLANIS) merupakan salah satu program dari Badan Pelaksana Jaminan Sosial (BPJS) Kesehatan. Program ini berupa suatu sistem pelayanan kesehatan dengan pendekatan proaktif yang dilaksanakan secara terintegrasi dan melibatkan Peserta, Fasilitas Kesehatan Tingkat Primer (FKTP) dan BPJS Kesehatan. Tujuan prolanis adalah untuk pemeliharaan kesehatan khususnya bagi peserta BPJS Kesehatan yang menderita penyakit kronis, agar mencapai kualitas hidup yang optimal dengan biaya pelayanan kesehatan yang efektif dan efisien serta dapat mencegah timbulnya komplikasi penyakit [3]. Kegiatan Prolanis meliputi aktifitas konsultasi medis atau edukasi, kunjungan rumah (home visit), reminder, aktifitas klub dan pemantauan status kesehatan secara berkala dan termonitor.

Pendokumentasian yang lengkap, sesuai, tepat waktu dan tepat waktu sangat dibutuhkan untuk keberlangsungan pelayanan kesehatan dalam mendukung pelayanan paripurna pada pasien dengan diagnosa penyakit kronis. Clinical Documentation Improvement (CDI) merupakan program yang memfasilitasi terwujudnya akurasi dari status klinis pasien yang akan menjadi data kode. Data kode tersebut akan ditranslasi menjadi pelaporan yang berkualitas, kartu pelaporan medis, kebutuhan data untuk pembiayaan, data kesehatan masyarakat, pelaporan dan register penyakit [1] Akurasi dari pendokumentasian klinis sangat diperlukan terutama pada pengelolaan pasien dengan diagnosa penyakit kronis. Peralihan pendokumentasian klinis dari manual ke sistem berbasis elektronik sangat disarankan karena dapat meningkatkan tepat waktu informasi dan kepuasan tenaga medis [14].

Klinik Sakinah Kaliurang Jember merupakan salah satu FKTP yang sudah bekerja sama dengan pihak BPJS terkait Prolanis sejak tahun 2014. Kegiatan Prolanis yang rutin dilakukan adalah perhitungan berat badan,tinggi badan, tensi, cek gula darah, konsultasi medis dan senam yang dilakukan satu bulan sekali. Pasien Prolanis pada Klinik Sakinah berjumlah 27 pasien, dari jumlah pasien tersebut $55,5 \%$ adalah penderita hipertensi, $44,4 \%$ adalah penderita diabetes melitus, dan 70,3\% dari jumlah pasien prolanis tersebut memiliki status gizi lebih.

Pengelolaan status kesehatan pasien prolanis dengan menggunakan aplikasi berbasis web telah di implementasikan di klinik Sakinah. Hasil analisis capaian kualitas informasi khususnya aspek ketepatan waktu sangat perlu diketahui untuk penyempurnaan sistem berbasis elektronik yang digunakan. Selain tujuan CDI untuk memaksimalkan pelaksanaan program prolanis, penerapan aplikasi berbasis elektronik ini juga terkait pemenuhan tuntutan ketepatan waktu pelaporan pihak Fasilitas Kesehatan Tingkat Primer (FKTP) kepada pihak BPJS kesehatan. Adapun pelaporan rutin kepada pihak BPJS Kesehatan terkait kegiatan prolanis dapat dibuat lebih mudah dalam perekapan data jika dibantu oleh sebuah aplikasi elektronik, namun aspek ketepatan waktu menjadi kunci utama dalam capaian pelaporan.

\section{PROLANIS}

Program Pengelolaan Penyakit Kronis (PROLANIS) adalah suatu sistem pelayanan kesehatan dan pendekatan proaktif yang dilaksanakan secara terintegrasi yang melibatkan peserta, fasilitas kesehatan dan BPJS kesehatan dalam rangka pemeliharaan kesehatan bagi peserta BPJS Kesehatan yang menderita penyakit kronis untuk mencapai kualitas hidup yang optiman dengan biaya pelayanan kesehatan yang efektif dan efisien. Dimana penyakit kronis yang dimaksud adalah Hipertensi dan Diabetes Melitus [3].

Prolanis merupakan salah satu program dari BPJS Kesehatan. Program ini berupa suatu sistem pelayanan kesehatan dengan pendekatan proaktif yang dilaksanakan secara terintegrasi dan melibatkan Peserta, FKTP dan BPJS Kesehatan. Tujuan prolanis adalah untuk pemeliharaan kesehatan khususnya bagi peserta BPJS Kesehatan yang menderita penyakit kronis, agar mencapai kualitas hidup yang optimal dengan biaya pelayanan kesehatan yang efektif dan efisien serta dapat mencegah timbulnya komplikasi penyakit [3].

PENYAKIT KRONIS

Penyakit kronis dalam program pengelolaan BPJS Kesehatan terdiri dari dua diagnosa penyakit, yaitu diabetes mellitus dan hipertensi. Diabetes mellitus merupakan suatu penyakit menahun atau kronis yang ditandai oleh hipergllikemia, yaitu kadar glukosa darah melebihi nilai normal. Penyakit yang biasa disebut diabetes atau DM ini akan menimbulkan komplikasi yang berakibat fatal, seperti penyakit jantung, penyakit ginjal, kebutaan, amputasi, dan mudah mengalami aterosklerosis jika dibiarkan tidak terkendali [12].

Hipertensi atau secara awam dikenal dengan tekanan darah tinggi adalah peningkatan tekanan darah sistolik lebih dari $140 \mathrm{mmHg}$ dan tekanan darah diastolik lebih dari 90 mmHg pada dua kali pengukuran, dengan selang waktu lima menit pada keadaan cukup istirahat atau tenang saat dilakukan pengukuran. Peningkatan tekanan darah yang berlangsung dalam jangka waktu lama (persisten) dapat menimbulkan kerusakan pada ginjal (gagal ginjal), jantung (penyakit jantung koroner) dan otak (menyebabkan stroke) bila tidak dideteksi secara dini dan mendapat pengobatan yang memadai [9].

\section{CLINICAL DOCUMENTATION IMPROVEMENT (CDI)}

Clinical Documentation Improvement (CDI) merupakan program yang memfasilitasi terwujudnya akurasi dari status klinis pasien yang akan menjadi data kode. Data kode tersebut akan ditranslasi menjadi pelaporan yang berkualitas, kartu pelaporan medis, kebutuhan data untuk pembiayaan, data kesehatan masyarakat, pelaporan dan register penyakit [1]. Pendokumentasian klinis di Indonesia dikenal dengan nama rekam medis.

Rekam medis berdasarkan Undang-Undang Republik Indonesia Nomor 29 Tahun 2004 adalah berkas yang berisikan catatan dan dokumen tentang identitas pasien, pemeriksaan, pengobatan, tindakan, dan pelayanan lain yang telah diberikan kepada pasien. Apabila terdapat kesalahan dalam melakukan pencatatan pada rekam medis, berkas dan catatan tidak boleh dihilangkan atau dihapus dengan cara apapun.

Tujuan rekam medis terbagi menjadi dua yaitu tujuan primer dan tujuan sekunder, yang paling berhubungan langsung dengan pelayanan pasien yaitu primer dan yang 
berkaitan dengan linkungan seputar pelayanan pasien namun tidak berhubungan langsung secara spesifik (sekunder) [6]. Tujuan utama (primer) rekam kesehatan terbagi dalam 5 (lima) kepentingan yaitu untuk :

a. Pasien, rekam kesehatan merupakan alat bukti utama yang mampu membenarkan adanya pasien dengan identitas yang jelas dan telah mendapatkan berbagai pemeriksaan dan pengobatan di sarana pelayanan kesehatan dengan segala hasil serta konsekuensi biayanya.

b. Pelayanan Pasien, rekam kesehatan mendokumentasikan pelayanan yang diberikan oleh tenaga kesehatan, penunjang medis dan tenaga lain yang bekerja dalam berbagai fasilitas pelayanan kesehatan. Demikian rekaman itu membantu pengambilan keputusan tentang terapi, tindakan dan penentuan diagnosa pasien.

c. Manajemen Pelayanan, Rekam kesehatan yang lengkap memuat segala aktivitas yang terjadi dalam manajemen pelayanan sehingga digunakan dalam menganalisis berbagai penyakit, menyusun pedoman praktik serta untuk mengevaluasi mutu pelayanan yang diberikan.

d. Menunjang Pelayanan, Rekam Kesehatan yang rinci akan mampu menjelaskan aktivitas yang berkaitan dengan penanganan sumber sumber yang ada pada organisasi pelayanan di rumah sakit, menganalisis kecendrungan yang terjadi dan mengomunikasikan informasi di antara klinik yang berbeda.

e. Pembiayaan, Rekam Kesehatan yang tepat waktu mencatat segala pemberian pelayanan kesehatan yang diterima pasien, Informasi ini menentukan besarnya pembayaran yang harus dibayar, baik secara tunai atau melalui asuransi.

\section{APLIKASI DAN KUALITAS INFORMASI}

Aplikasi adalah koleksi window dan objek-objek yang menyediakan fungsi untuk aktivitas user, seperti pemasukan data, proses dan pelaporan. Berkembangan jaman, aplikasi yang banyak digunakan adalah aplikasi berbasis web. Web adalah jaringan komputer yang terdiri dari kumpulan situs internet yang menawarkan teks dan grafik dan suara dan sumber daya animasi melalui hypertekx transfer protocol [16].

Kualitas informasi adalah suatu fungsi yang menyangkut nilai dari keluaran informasi yang dihasilkan oleh sistem. Berdasarkan beberapa pendapat para ahli, dapat disimpulkan bahwa kualitas informasi adalah suatu pengukuran yang berfokus pada keluaran yang diproduksi oleh sistem, serta nilai dari keluaran bagi pengguna. [4] Kualitas informasi terdiri tiga hal, yaitu:

a. Tepat waktu, informasi harus bebas dari kesalahankesalahan dan tidak bias atau menyesatkan. Informasi harus memiliki ketepat waktuan tertentu agar tidak diragukan kebenarannya.

b. Tepat pada waktunya, informasi yang datang pada penerima tidak boleh datang terlambat, karena informasi yang datang tidak tepat waktu, tidak bernilai lagi, sebab informasi digunakan dalam proses pembuatan keputusan.

c. Kesesuaian, informasi yang ada memiliki nilai kemanfaatan sesuai dengan yang dibutuhkan oleh pemakainya. Informasi emmiliki tingkat relativitas yang berbeda, tergantung pada tingkat pemakai.
Kualitas informasi juga terdapat kelengakpan dan kepuasan pengguna [13].

a. Kelengkapan, kelengkapan isi dari informasi yang dihasilkan oleh sistem informasi.Informasi yang lengkap adalah informasi yang mencakup seluruh informasi yang dibutuhkan oleh pengguna sistem informasi tersebut.

b. Kepuasan, merupakan respon dan umpan balik yang dimunculkan pengguna setelah memakai sistem informasi.

Kualitas informasi mempunyai atribut-atribut seperti informasi yang diperoleh dari sebuah sistem, ketepat waktuan informasi, relevansi informasi, ketepatan waktu (timelines), dan tepat waktu informasi dan kepuasan pengguna [10].

\section{METODE PENELITIAN}

Jenis penelitian dalam penelitian ini adalah penelitian deskriptif dan analitik kuantitatif dengan pendekatan cross sectional. Cross sectional yaitu rancangan penelitian dengan pada pengukurannya dilakukan pada saat bersamaan atau sekali waktu. Penelitian deskriptif bertujuan untuk menyajikan data secara sistematis sehingga dapat lebih mudah dipahami. Analisis kuantitatif untuk mendukung penelitian ini digunakan skala likert untuk mengetahui nilai masing-masing variabel.

Teknik Pengambilan Sampel pada penelitian ini menggunakan rumus cross sectional dalam penelitian ini diperoleh sebanyak 24 orang dari populasi sebanyak 30 orang yang terkait dengan penggunaan aplikasi pemantauan rutin pasien program pengelolaan penyakit kronis berbasis web. Adpun teknik pengambilan sampel dengan menggunakan teknik systematic random sampling. Systematic random sampling merupakan teknik pengambilan sampel secara acak dengan interval tertentu dari suatu kerangka sampel yang telah diurutkan.

Penelitian ini menggunakan kuisioner yang berisi item-item pertanyaan mengenai kualitas informasi dari aplikasi yang digunakan. Instrumen yang telah disusun berupa kuesioner yang telah diuji validitas dan reliabitas mengguanakn uji Korelasi Pearson Product Moment. Penelitian ini dilakukan selama 3 bulan yaitu pada bulan Juni 2019 sampai Agustus 2019 di salah satu fasilitas pelayanan primer yang mengelola pasien prolanis BPJS di kabupaten jember. Uji validitas dan reliabilitas instrumen dilakukan di klinik prolanis dengan karakteristik yang hampir menyerupai yaitu pada fasilitas pelayanan primer serupa yang mengelola pasien prolanis BPJS di kabupaten Jember. Pengumpulan data dilakukan post penerapan aplikasi pemantauan rutin pasien program pengelolaan penyakit kronis berbasis web. Pengolahan data yang dilakukan dalam penelitian ini meliputi :

a. Editing: Proses pengolahan data editing dilakukan pada saat pengumpulan data. Editing bertujuan untuk memeriksa apakah ada data yang belum lengkap atau terdapat kekeliruan dalam pengisian kuisioner.

b. Coding: Proses pemberian simbol atau kode untuk tiap data dalam setiap kategori yang terdapat dalam kuisioner.

c. Entry: Entry data merupakan proses memasukan data ke dalam aplikasi pengolah data dalam penelitian ini menggunakanan aplikasi Microsoft Excel yang 
dilakukan setelah proses pengkodean setiap pertanyaan pada kuisioner.

d. Tabulating: Tabulasi merupakan suatu proses menempatkan data dalam bentuk tabel. Tabel yang dibuat ringkas dan berisikan data sesuai dengan kebutuhan peneliti yang digunakan untuk analisis. Teknik analisis data dengan menggunakan metode skoring, yaitu setiap variabel yang terdapat pada aspek tepat waktu kualitas informasi yang diukur melalui item pertanyaan pada kuesioner yang diberikan kepada responden.

\section{HASIL DAN PEMBAHASAN}

Hasil pengukuran aspek tepat waktu pada kualitas informasi (tersaji pada gambar 1) diperoleh hasil tertinggi pada item data pasien sebesar $83,3 \%$ dan terendah pada item data petugas dan laporan DM sebesar $73,3 \%$. Seluruh data pasien dapat diakses secara mudah dan tepat waktu. Data pasien tersebut sangat dibutuhkan oleh pihak klinik sebagai pelayanan pengelolaan penyakit kronis juga sebagai rekapan data untuk pelaporan kepada pihank BPJS Kesehatan selaku penyelenggara pembiayaan jaminan kesehatan nasional.

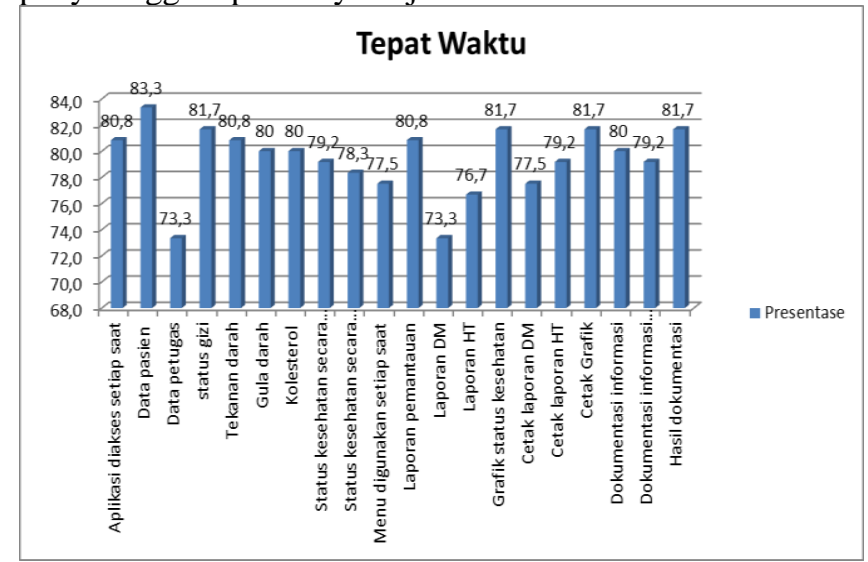

Gambar 1. Presentase Hasil Pengukuran Variabel Tepat Waktu

Adapun hasil pengukuran dengan nilai rendah terdapat pada item data petugas dan laporan DM. Aplikasi prolanis belum menampilkan data petugas pemeriksa kesehatan sebagai bukti kualitas pelayanan kesehatan yang diberikan kepda masyarakat. Harapan dari responden sebagai pengguna aplikasi agar aplikasi prolanis dapat menyajikan semua data baik data pasien maupun data petugas secara realtime. Laporan yang dihasilkan juga seharusnya dapat bermanfaat bagi pasien.

Hasil rangkuman item aspek tepat waktu kualitas informasi dari aplikasi prolanis tersaji pada tabel berikut:

Tabel 1. Item Aspek Tepat waktu Kualitas Informasi

\begin{tabular}{|l|l|l|l|}
\hline No & \multicolumn{1}{|c|}{ Item Pertanyaan } & \multicolumn{1}{|c|}{ Item } & \% \\
\hline 1 & $\begin{array}{l}\text { Aplikasi dapat di akses setiap } \\
\text { saat }\end{array}$ & $\begin{array}{l}\text { Aplikasi } \\
\text { diakses setiap } \\
\text { saat }\end{array}$ & 80,8 \\
\hline 2 & $\begin{array}{l}\text { Dapat mengakses data pasien } \\
\text { setiap saat }\end{array}$ & Data pasien & 83,3 \\
\hline 3 & $\begin{array}{l}\text { Dapat mengakses data petugas } \\
\text { setiap saat }\end{array}$ & Data petugas & 73,3 \\
\hline 4 & $\begin{array}{l}\text { Dapat mengakses data status } \\
\text { gizi setiap saat }\end{array}$ & status gizi & 81,7 \\
\hline 5 & $\begin{array}{l}\text { Dapat mengakses data tekanan } \\
\text { darah setiap saat }\end{array}$ & $\begin{array}{l}\text { Tekanan } \\
\text { darah }\end{array}$ & 80,8 \\
\hline 6 & $\begin{array}{l}\text { Dapat mengakses data gula } \\
\text { darah setiap saat }\end{array}$ & Gula darah & 80 \\
\hline
\end{tabular}

\begin{tabular}{|c|c|c|c|}
\hline 7 & $\begin{array}{l}\text { Dapat mengakses data lipid } \\
\text { (kolesterol) setiap saat }\end{array}$ & Kolesterol & 80 \\
\hline 8 & $\begin{array}{lrr}\begin{array}{l}\text { Dapat memantau } \\
\text { kesehatan }\end{array} & \text { status } \\
\text { periodik } & & \text { secara } \\
\end{array}$ & $\begin{array}{l}\text { Status } \\
\text { kesehatan } \\
\text { secara } \\
\text { periodik } \\
\end{array}$ & 79,2 \\
\hline 9 & $\begin{array}{l}\text { Dapat memantau status } \\
\text { kesehatan pasien } \\
\text { berkelanjutan }\end{array}$ & $\begin{array}{l}\text { Status } \\
\text { kesehatan } \\
\text { secara } \\
\text { berkelanjutan }\end{array}$ & 78,3 \\
\hline 10 & $\begin{array}{l}\text { Menu-menu pada aplikasi } \\
\text { dapat digunakan dengan setiap } \\
\text { saat }\end{array}$ & $\begin{array}{l}\text { Menu } \\
\text { digunakan } \\
\text { setiap saat }\end{array}$ & 77,5 \\
\hline 11 & $\begin{array}{l}\text { Menghasilkan laporan hasil } \\
\text { pemantauan rutin dengan tepat } \\
\text { waktu }\end{array}$ & $\begin{array}{l}\text { Laporan } \\
\text { pemantauan }\end{array}$ & 80,8 \\
\hline 12 & $\begin{array}{l}\text { Menyajikan laporan hasil } \\
\text { pemantauan rutin pasien DM } \\
\text { secara periodik }\end{array}$ & Laporan DM & 73,3 \\
\hline 13 & $\begin{array}{l}\text { Menyajikan laporan hasil } \\
\text { pemantauan rutin pasien } \\
\text { hipertensi secara periodik }\end{array}$ & Laporan HT & 76,7 \\
\hline 14 & $\begin{array}{l}\text { Menyajikan grafik status } \\
\text { kesehatan (status gizi, tekanan } \\
\text { darah, gula darah, kolesterol) } \\
\text { secara periodik }\end{array}$ & $\begin{array}{l}\text { Grafik status } \\
\text { kesehatan }\end{array}$ & 81,7 \\
\hline 15 & $\begin{array}{l}\text { Dapat mencetak laporan hasil } \\
\text { pemantauan rutin pasien DM } \\
\text { setiap saat }\end{array}$ & $\begin{array}{l}\text { Cetak laporan } \\
\text { DM }\end{array}$ & 77,5 \\
\hline 16 & $\begin{array}{l}\text { Dapat mencetak laporan hasil } \\
\text { pemantauan rutin pasien } \\
\text { hipertensi setiap saat }\end{array}$ & $\begin{array}{l}\text { Cetak laporan } \\
\text { HT }\end{array}$ & 79,2 \\
\hline 17 & $\begin{array}{l}\text { Dapat mencetak grafik status } \\
\text { kesehatan (status gizi, tekanan } \\
\text { darah, gula darah, kolesterol) } \\
\text { setiap saat }\end{array}$ & Cetak Grafik & 81,7 \\
\hline 18 & $\begin{array}{l}\text { Dapat mendokumentasikanan } \\
\text { informasi dengan tepat waktu }\end{array}$ & $\begin{array}{l}\text { Dokumentasi } \\
\text { informasi }\end{array}$ & 80 \\
\hline 19 & $\begin{array}{l}\text { Dapat mendokumentasikan } \\
\text { informasi secara periodik }\end{array}$ & $\begin{array}{l}\text { Dokumentasi } \\
\text { informasi } \\
\text { Periodik } \\
\end{array}$ & 79,2 \\
\hline 21 & $\begin{array}{ll}\text { Dapat mengakses hasil } \\
\text { dokumentasi setiap saat }\end{array}$ & $\begin{array}{l}\text { Hasil } \\
\text { dokumentasi }\end{array}$ & 81,7 \\
\hline
\end{tabular}

Sumber : Penelitian Prolanis, 2019.

Penentuan kategori interpretasi skor yang diperoleh berdasarkan jawaban responden terkait variabel aspek tepat waktu kualitas informasi dari implementasi aplikasi adalah kategori baik, berdasarkan pengukuran sebagai berikut:

\section{Kriteria Jawaban pada Variabel Tepat} Waktu

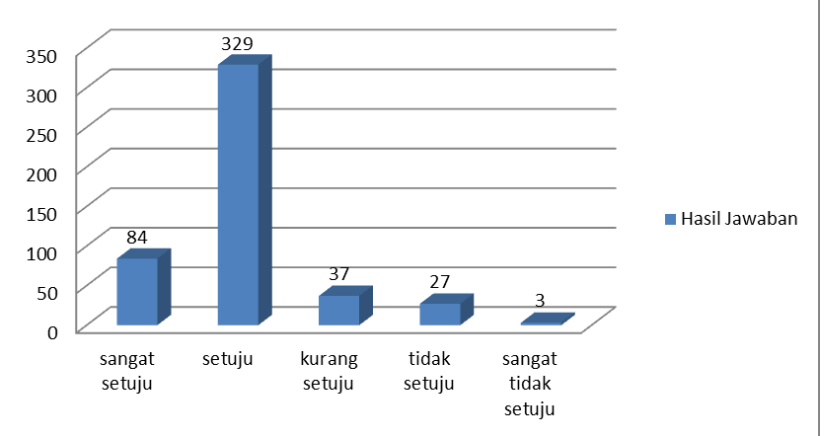

Gambar 2. Kriteria Jawaban Variabel Tepat waktu 
Gambar diatas menjelaskan bahwa jawaban tertinggi berada pada kriteria setuju sebesar 329 dari total jawaban item pertanyaan terkait aspek tepat waktu kualitas informasi yang diberikan kepada responden. Hasil total skor dikalikan jumlah jawaban dari item pertanyaan diperoleh sebesar 2400, sehingga interpretasi skor diperoleh melalui penghitungan berdasarkan skor ideal sebagai berikut:

\section{Perhitungan Skor Ideal :}

$\begin{array}{cccc}\text { Jumlah Skor Ideal : } & \text { Skor Tertinggi X } & \sum \mathrm{nX} & \text { } \\ : & 5 \mathrm{X} & 24 \mathrm{X} & 20 \\ : & 2400 & & \end{array}$

Perhitungan Interpretasi Skor :

\begin{tabular}{ccc} 
Interpretasi Skor : & Jumlah Skor & X 100\% \\
\cline { 2 - 3 } & $:$ & Skor Ideal \\
\cline { 2 - 3 } & 1904 & X 100\% \\
& 2400 &
\end{tabular}

Hasil perhitungan interpretasi skor pada variabel tepat waktu didapatkan hasil sebesar 79,3\%. Hasil tersebut menunjukan bahwa nilai $79,3 \%$ berada pada kategori baik berdasarkan tabel interpretasi skor berikut:

Tabel 3.1 Interpretasi Skor Evaluasi

\begin{tabular}{|c|c|}
\hline Persentase & Kriteria \\
\hline Angka 0\%-20\% & Sangat Kurang \\
\hline Angka $21 \%-40 \%$ & Kurang \\
\hline Angka $41 \%-60 \%$ & Cukup \\
\hline Angka $61 \%-80 \%$ & Baik \\
\hline Angka $81 \%-100 \%$ & Sangat Baik \\
\hline
\end{tabular}

Sumber: Riduwan dan Sunarto, 2011, Pengantar Statistika hal.23

Variabel tepat waktu berada pada kategori baik karena telah mampu membuat dan menyajikan grafik serta laporan pemantauan status kesehatan pasien prolanis dengan tepat waktu. Aplikasi ini dapat di akses oleh pasien secara online dan dapat diakses setiap saat. Aplikasi ini berguna sebagai media informasi dari FKTP kepada pasien prolanis. FKTP dihimbau untuk merancang desain komunikasi dan propaganda mengenai materi penyuluhan dan edukasi kesehatan yang berkaitan dengan pencegahan penyakit, seperti peningkatan aktivitas fisik, pengaturan pola makan, dan program pengelolaan penyakit diabetes mellitus dan hipertensi [2].

Kelebihan sistem prolanis juga menghasilkan laporan dan riwayat pemeriksaan yang dapat ditampilkan secara tepat waktu sehingga mampu menunjang program CDI dalam meningkatkan kualitas ketepatan data dan informasi yang dihasilkan sistem informasi kesehatan. CDI yang baik akan berdampak terhadap perawatan pasien dengan menyediakan informasi untuk berbagai pihak mulai dari pemberi pelayanan dan juga penerima pelayanan sehingga mampu menghasilkan informasi yang berkualitas terkait tren dan jejak penyakit, kesehatan masyarakat, pelaporan, translasi data kode serta reimbursment yang sesuai [15].

Aplikasi prolanis juga menyimpan data pasien secara aman dan secara periodik setiap bulan. Penyimpanan secara periodik ini mendukung aspek medikolegal dikarenakan data riwayat pemeriksaan pasien telah tersimpan dan dapat ditampilkan secara realtime bagi semua pasien. Penyimpanan informasi yang akurat dan secara periodik akan berdampak pada peningkatan keamanan dan kualitas pelayanan medis serta fungsi medikolegal [7]. Data identitas pasien yang akurat akan membantu dalam Sistem Pendukung Keputusan Klinis. Manfaat tersebut yaitu meningkatkan keselamatan pasien, mengurangi kesalahan data medis, meningkatkan akurasi perawatan serta kualitas layanan. Dukungan sistem elektronik dalam pelayanan kesehatan dapat meningkatkan kualitas patient safety, mengurangi medical errors, meningkatkan kualitas pelayanan kesehatan [8].

Hasil perhitungan interpretasi skor terdapat 2 item yang memiliki nilai rendah yaitu data petugas dan laporan DM. Aplikasi prolanis belum menampilkan jumlah data petugas pemeriksa kesehatan yang memang harus disediakan untuk menangani pasien prolanis dengan pelayanan terbaik dan berkompeten. FKTP tentu seharusnya sudah mempertimbangkan ketersediaan sumber daya yang berkompeten disediakan untuk merawat seluruh pasien [17].

Aplikasi prolanis menyajikan pelaporan DM dan hipertensi hanya dalam bentuk grafik dan tabel saja. Belum terdapat pelaporan berupa notifikasi sebagai pengingat batas tidak normal status kesehatan pasien prolanis. Belum terdapat notifikasi (IMT, tekanan darah, kadar gula darah, kolesterol) yang melebihi batas normal. Notifikasi ini berguna sebagai pencegahan bagi pasien prolanis tersebut. Kegiatan Prolanis ini mencakup upaya-upaya pencegahan komplikasi berlanjut dan peningkatan kesehatan masyarakat [10]. Notifikasi juga berfungsi sebagai pengingat status kesehatan pasien yang bermanfaat untuk proses skrinning kesehatan. An information technology-enabled quality improvement initiative to notify coordinators of screening recalls in real time [5].

\section{KESIMPULAN}

Aspek tepat waktu pada kualitas informasi yang dihasilkan dari suatu penerapan sistem elektronik sangat dibutuhkan untuk keberlangsungan pelayanan kesehatan. Hal tersebut untuk mendukung kualitas pelayanan kesehatan, membantu sistem pendukung keputusan serta pencegahan komplikasi berlanjut khususnya kebutuhan informasi dalam pengelolaan pasien prolanis. Hasil analisis kualitas informasi khususnya aspek tepat waktu terkait penerapan aplikasi prolanis diperoleh interpretasi skor secara keseluruhan berada pada kategori baik (79,3\%). Item aspek tepat waktu tertinggi terdapat pada item identitas pasien sesuai kartu BPJS dan grafik kesehatan sebesar $83,3 \%$ dan item terendah pada data petugas dan laporan DM sebesar 73,3\%. Hasil analisis tersebut ditujukan untuk dapat menyempurnakan aplikasi prolanis yang telah dibuat agar tepat sasaran sesuai kebutuhan khususnya keperluan CDI.

\section{REFERENSI}

[1] AHIMA. 2018. Clinical Documentation Improvement. Diakses dari https://www/ahima.org/topics/cdi

[2] Arifa, Auliya. 2018. Pengaruh Informasi Pelayanan Prolanis Dan Kesesuaian Waktu Terhadap Pemanfaatan Prolanis Di Pusat Layanan Kesehatan Unair. Jurnal Administrasi Kesehatan Indonesia Volume 6 No 2 July-December 2018.

[3] BPJS Kesehatan. Buku Panduan Praktis Prolanis (Program Pengelolaan Penyakit Kronis). Jakarta. 2015 
[4] Buana, dkk. 2018. Pengaruh Kualitas Sistem Informasi, Kualitas Informasi, dan Perceived Usefulness Pada Kepuasan Pengguna Sistem Informasi Akuntansi. https://ojs.unud.ac.id

[5] Catherine ett all. 2019. Impact of an Information TechnologyEnabled Quality Improvement Initiative on Timeliness of Patient Contact and Scheduling of Screening Mammography Recall. https://www.ajronline.org/doi/10.2214/AJR.19.21397

[6] Hatta, Gemala. 2018. Kualitas Pendokumentasian RK http://bplushealthpartner.com/Materi\%20ibu\%20Gemala.pdf

[7] Karimah, Rinda dan Wicaksono Andri. 2018. Prototype Sistem Informasi Pelayanan Bayi Baru Lahir pada Fasilitas Kesehatan Primer. Jurnal Khazanah Informatika Vol. 4 No. 1 Juni 2018

[8] Karimah, dkk. 2018. Design of Clinical Decision Support System (CDSS) based on Integrated Childhood Illness Management (ICIM) at Primary Health Care Centre. https://publikasi.polije.ac.id/index.php/ProceedingICOFA/article/vie w/1369

[9] Kemenkes RI. Buku Kesehatan Ibu dan Anak. Jakarta. Kementrian Kesehatan RI dan JICA. 2016

[10] Meiriana, dkk. 2019. Implementasi Program Pengelolaan Penyakit Kronis (Prolanis) Pada Penyakit Hipertensi Di Puskesmas Jetis Kota Yogyakarta Jurnal Kebijakan Kesehatan Indonesia : JKKI, Vol. 08, No. 02 Juni 2019
[11] Prawirosumarto. 2016. Pengaruh Kualitas Sistem, Kualitas Informasi, dan Kualitas Layanan Terhadap Kepuasan Pengguna Sistem ELearning. Jurnal Ilmiah Manajemen, Volume VI, No. 3

[12] Rasjmida. Diet Sehat Untuk PenderitaDiabetes Mellitus.Jakarta Timur: Penebar Swadaya. 2015

[13] Saputro, P.H. dkk. 2015. Model Delone and Mclean untuk Mengukur Kesuksesan E-government Kota Pekalongan. Scientific Journal of Informatics Vol. 2, No.1. http://journal.unnes.ac.id/nju/index.php/sji e-ISSN 2460-0040

[14] Setyaningrum, dkk. 2016. Peningkatan Kelengkapan Dokumentasi Dan Kepuasan Pewarat Pada Pengawasan Hospital Acquired Infections (HAIs) Berbasis Komputer. Jurnal Keperawatan Indonesia, Vol 19 No 1 hal 33-40.

[15] Shepheard, Jennie. 2018. What Do We Really Want From Clinical Documentation Improvement Programs ?. Health Information Management Journal. Vol 47(1) 3-5.

[16] Sidik, Beta. Pemrograman Web Dengan PHP, Bandung: Informatika. 2014

[17] Widaty, D. (2017). Indikator Pembayaran Kapitasi Berbasis Pemenuhan Komitmen Pelayanan pada Fasilitas Kesehatan Tingkat Pertama di Surabaya'. Jurnal Administrasi Kesehatan Indonesia, 5(2), pp. 111-116. Available at: https://ejournal.unair.ac.id/JAKI/article/download/454 8/pdf. 